\title{
Badania właściwości stopów lutowniczych na bazie eutektyki Zn-Al z dodatkiem miedzi
}

\section{Research on the properties solder alloys based on Al-Zn eutectic with the addition of copper}

\section{Streszczenie}

W artykule przedstawiono wyniki badań lutu bezołowiowego do lutowania miękkiego wysokotemperaturowego z przeznaczeniem do lutowania płomieniowego stopów mosiężnych i aluminiowych. Opracowano stop na osnowie eutektyki Zn-Al i badano wpływ dodatku 0,5; 1,0; 1,5 at. \% Cu. Przeprowadzono wytop stopów o założonym składzie na podstawie danych literaturwych, a także układów fazowych dwu- i trójskładnikowych. Wykonano pomiary rozpływności i zwilżalności (temperatura $500^{\circ} \mathrm{C}$, topnik Eurotop Al700) oraz badania mikrostruktury złączy lutowanych.

\section{Wstęp}

Ze względu na wzrastającą ilość odpadów elektronicznych i elektrycznych zawierających luty ze szkodliwymi dla zdrowia i środowiska metalami, wiele państw postanowiło ograniczyć ich stosowanie w przemyśle. Wprowadzenie nowych przepisów wymusiło na producentach i ośrodkach naukowych rozpoczęcie badań nad nowymi stopami lutowniczymi $[1 \div 3]$. Prace badawcze dotyczyły bezołowiowych stopów, głównie na osnowie cyny z dodatkiem srebra, miedzi lub cynku $[4 \div 7]$. Badania nad ekologicznymi lutami dotyczyły różnych zastosowań, dlatego kolejnym krokiem były badania nad stopami lutowniczymi z przeznaczeniem do pracy w podwyższonej temperaturze. Eksperymenty skupiały się na stopach na osnowie Zn-Al [8, 9]. Prace różnych ośrodków naukowych, m.in. zespołu Vianco, który

Mgr inż. Sylwia Mosińska, dr inż. Artur Lange Politechnika Wrocławska; dr inż. Janusz Pstruś, dr inż. Tomasz Gancarz - Polska Akademia Nauk w Krakowie. pracował nad stopami mającymi zakres temperatury pracy powyżej $300^{\circ} \mathrm{C}$ [10], ale także prace Takaku [11], Kanga [12] oraz Savaskana [13] przyczyniły się do poszerzenia wiedzy na temat lutów na bazie Zn-Al. W literaturze naukowej coraz więcej uwagi poświęca się badaniom nad fazami międzymetalicznymi powstałymi pomiędzy $\mathrm{Cu}$ a stopami okołoeutektycznymi

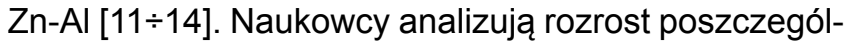
nych faz, gdyż mają one duży wpływ na zachowanie się lutowiny w warunkach eksploatacyjnych.

\section{Badania}

Do wszystkich pomiarów użyto stopów przygotowanych w komorze o wysokiej czystości - zawartość pary wodnej poniżej 1 ppm, zawartość tlenu poniżej 1 ppm. Czystość użytych metali: $\mathrm{Al}, \mathrm{Cu}, \mathrm{Zn}$ oraz podkładka z Cu i Al - 99,995\%. Pomiary rozpływności prowadzono $z$ zastosowaniem topnika Eurotop Al700 w atmosferze ochronnej azotu w piecu do pomiaru zwilżalności 
metoda kropli leżącej. Warunkiem uzyskania połączenia lutowanego było zwilżenie lutem materiału łączonego $w$ warunkach procesu lutowania. Stąd badania właściwości lutowniczych spoiw dotyczą zwykle oceny ich zdolności do zwilżenia materiałów lutowanych w określonych warunkach technologicznych.

W przeprowadzonych badaniach lutowność stopu $\mathrm{Zn}-\mathrm{Al}$ z dodatkiem $\mathrm{Cu}$ oceniano na podstawie powierzchni rozpłynięcia się lutu $w$ atmosferze ochronnej; dokładny opis metody i aparatury zamieszczono w [14]. Pomiary prowadzono w powietrzu, odważone stopy lutownicze nakładano na oczyszczone płytki aluminiowe i miedziane, które pokryto wcześniej odpowiednią ilością topnika. Temperatura pracy wynosiła $500^{\circ} \mathrm{C}$. Powierzchnię rozpłynięcia się lutu mierzono po ostudzeniu próbek metodą graficzną opisaną w [15]. Jako miarę zwilżenia przyjmuje się kąt zwilżenia występujący w równaniu Younga-Dupree, opisującym drugie prawo teorii kapilarności, który mierzono w czasie rzeczywistym podczas pomiaru omówionego w [14], a także po ostudzeniu i oczyszczeniu próbek.

Zmierzone kąty zwilżania na podłożu miedzianym są wyższe niż kąty zwilżania na aluminium dla poszczególnych kompozycji stopowych. Wraz ze wzrostem zawartości miedzi w stopie eutektycznym Zn-Al zmniejsza się kąt zwilżania na obu podłożach. Kąty zwilżania na podłożach $\mathrm{Cu}$ i Al są mniejsze od $30^{\circ}$, co wskazuje na bardzo dobrą zwilżalność, zgodnie z klasyfikacją zwilżania wg Kleina-Wassinka [15].

Po pomiarach rozpływności zestalone krople lutu cięto prostopadle do płaszczyzny przez środek próbki. Aby określić mikrostrukturę złączy, próbki inkludowano

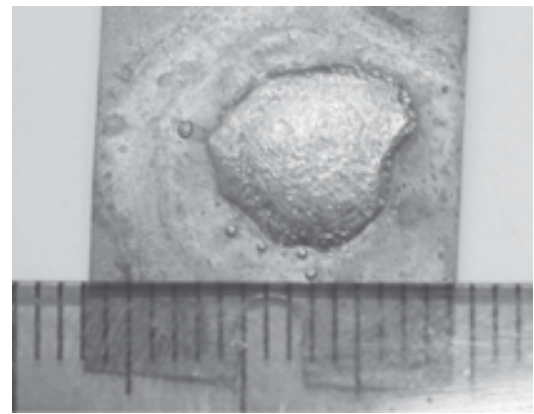

Rys. 1. Próbka po badaniu na rozpływność stopu $\mathrm{ZnAl+Cu}$ na podłożu miedzianym

Fig. 1. Wettability test of $\mathrm{ZnAl}+\mathrm{Cu}$ samples on copper substrate

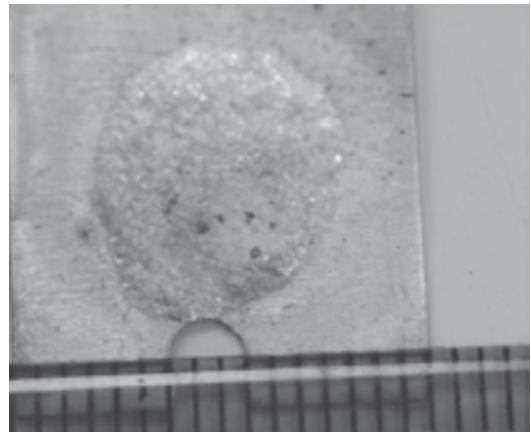

Rys. 2. Próbka po badaniu na rozpływność stopu $\mathrm{ZnAl}+\mathrm{Cu}$ na podłożu aluminiowym

Fig. 2. Wettability test of $\mathrm{ZnAl}+\mathrm{Cu}$ samples on aluminum substrate w żywicy epoksydowej, szlifowano i polerowano, a następnie napylano cienką warstwą węgla w celu ochrony przed utlenieniem i poprawy jakości obrazu SEM. Analizę mikrostruktury prowadzono przy napięciu $20 \mathrm{kV}$ w odległości $10 \mathrm{~mm}$ od próbki na skaningowym mikroskopie elektronowym (SEM, FEI ESEM XL30), wyposażonym w spektrometr energii promieniowania rentgenowskiego $z$ dyspersją energii (EDX) firmy EDAX. Dokonano analizy mikrostrukturalnej badanych próbek

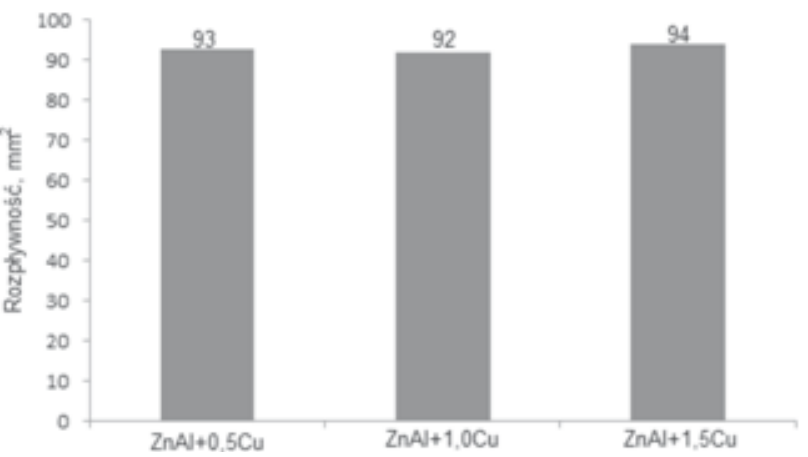

Rys. 3. Powierzchnia rozpłynięcia $0,5 \mathrm{~g}$ ciekłego lutu $(\mathrm{ZnAl})_{\text {eut }}+0,5$; 1,0 i $1,5 \%$ at. Cu po $3 \mathrm{~min}$ wygrzewania w temp. $500^{\circ} \mathrm{C}$ na podłożu miedzianym

Fig. 3. The spreading area of $0.5 \mathrm{~g}(\mathrm{ZnAl})_{\text {eut }}+0.5,1.0$ and $1.5 \%$ at. $\mathrm{Cu}$ liquid solder after 3 min exposure at the $500^{\circ} \mathrm{C}$ temperature on cooper substrate

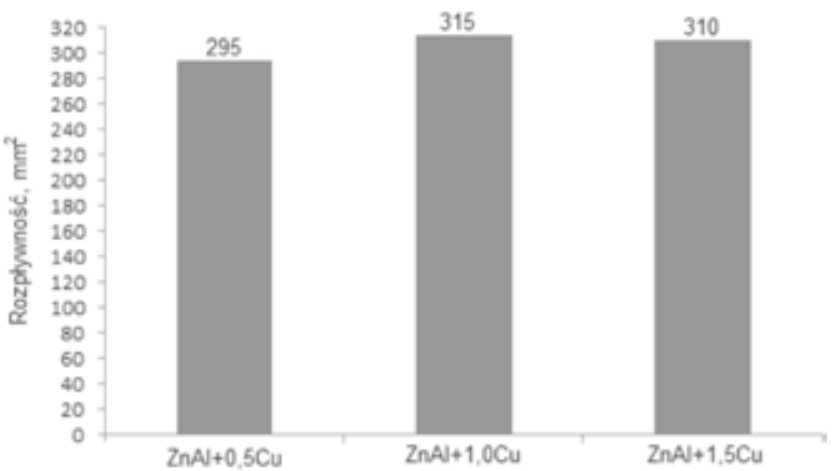

Rys. 4. Powierzchnia rozpłynięcia $0,5 \mathrm{~g}$ ciekłego lutu $(\mathrm{ZnAl})_{\text {eut }}+0,5$; $1,0 \mathrm{i} 1,5 \%$ at. $\mathrm{Cu}$ po $15 \mathrm{~s}$ wygrzewania w temperaturze $500^{\circ} \mathrm{C}$ na podłożu aluminiowym

Fig. 4. The spreading area of $0.5 \mathrm{~g}(\mathrm{ZnAl})_{\text {eut }}+0.5,1.0$ and $1.5 \%$ at. $\mathrm{Cu}$ liquid solder after $15 \mathrm{~s}$ exposure at the $500^{\circ} \mathrm{C}$ temperature on aluminum substrate

pod względem rozłożenia składników mikrostruktury oraz składu chemicznego. Wyniki przedstawiono na rysunkach $1 \div 4$.

Na rysunkach $5 \div 9$ pokazano mikrostrukturę złącza lutowanego $\mathrm{Zn}-\mathrm{Al}+(0,5 ; 1,0 ; 1,5) \%$ at. $\mathrm{Cu}$ na podłożu miedzianym. Temperatura wynosiła $500^{\circ} \mathrm{C}$, pomiar prowadzono w powietrzu. Na podstawie badań można stwierdzić, że za procesy zachodzące na granicy lutowina-podłoże odpowiada bogaty $w$ fazy międzymetaliczne stop Cu-Zn. Po roztopieniu lutu procesy zachodzące na granicy lutowina-podłoże można podzielić na dwa etapy. Pierwszy z nich obejmuje rozpuszczanie miedzi przez ciekły cynk, drugi - krystalizację i reakcję perytektyczną. Pierwsza krystalizuje faza $\varepsilon-C u Z n_{4}$, a później faza 


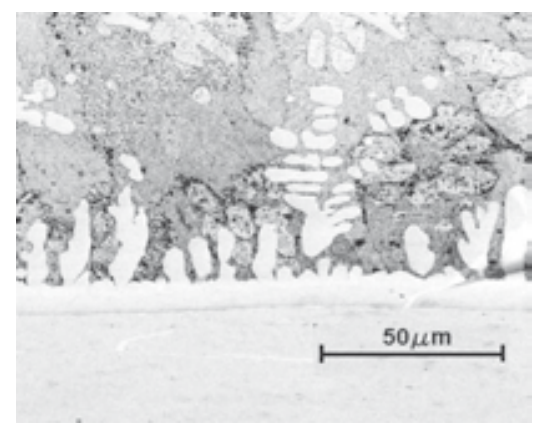

Rys. 5. Mikrostruktura złącza lutowanego ( $\mathrm{Zn}-\mathrm{Al})_{\text {eut }}+1,0 \%$ at. Cu na podłożu miedzianym $w$ temperaturze $500^{\circ} \mathrm{C}$, czas ekspozycji $15 \mathrm{~s}$ Fig. 5. Microstructure of solder joints $(\mathrm{Zn}-\mathrm{Al})_{\text {eut }}+1.0 \%$ at. $\mathrm{Cu}$ on the copper substrates at $500^{\circ} \mathrm{C}$, exposure time $15 \mathrm{~s}$

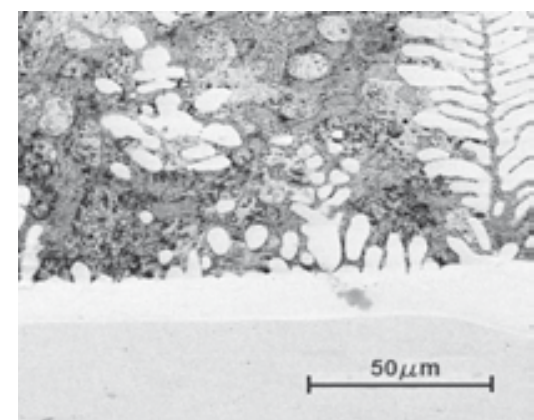

Rys. 6. Mikrostruktura złącza lutowanego ( $\mathrm{Zn}-\mathrm{Al})_{\text {eut }}+1,0 \%$ at. Cu na podłożu miedzianym w temperaturze $500^{\circ} \mathrm{C}$, czas ekspozycji $30 \mathrm{~s}$

Fig. 6. Microstructure of solder joints $(\mathrm{Zn}-\mathrm{Al})_{\text {eut }}+1.0 \%$ at. $\mathrm{Cu}$ on the copper substrates at $500^{\circ} \mathrm{C}$, exposure time $30 \mathrm{~s}$

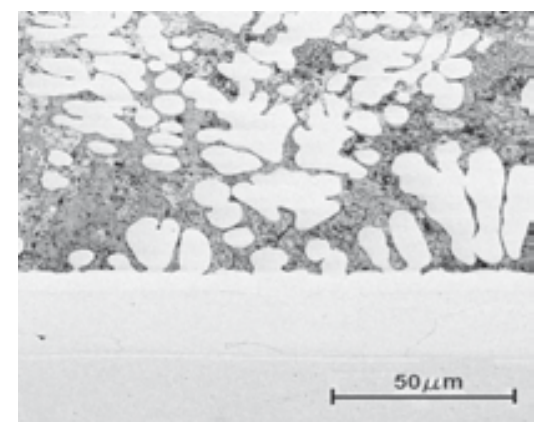

Rys. 7. Mikrostruktura złącza lutowanego (Zn-Al) $)_{\text {eut }}+1,0 \%$ at. Cu na podłożu miedzianym w temperaturze $500^{\circ} \mathrm{C}$, czas ekspozycji $60 \mathrm{~s}$

Fig. 7. Microstructure of solder joints $(\mathrm{Zn}-\mathrm{Al})_{\text {eut }}+1.0 \%$ at. $\mathrm{Cu}$ on the copper substrates at $500^{\circ} \mathrm{C}$, exposure time $60 \mathrm{~s}$

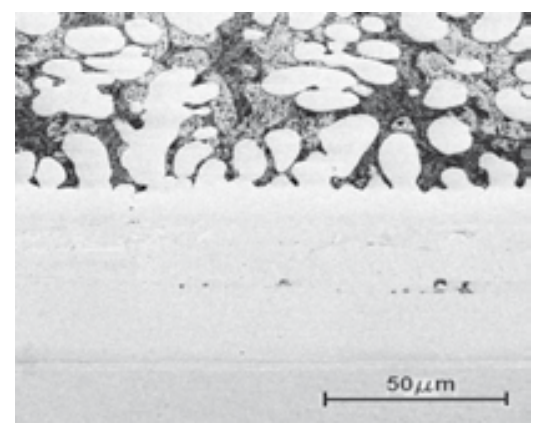

Rys. 8. Mikrostruktura złącza lutowanego (Zn-Al) $)_{\text {eut }}+1,0 \%$ at. Cu na podłożu miedzianym w temperaturze $500^{\circ} \mathrm{C}$, czas ekspozycji $120 \mathrm{~s}$ Fig. 8. Microstructure of solder joints $(\mathrm{Zn}-\mathrm{Al})_{\text {eut }}+1.0 \%$ at. $\mathrm{Cu}$ on the copper substrates at $500^{\circ} \mathrm{C}$, exposure time $120 \mathrm{~s}$

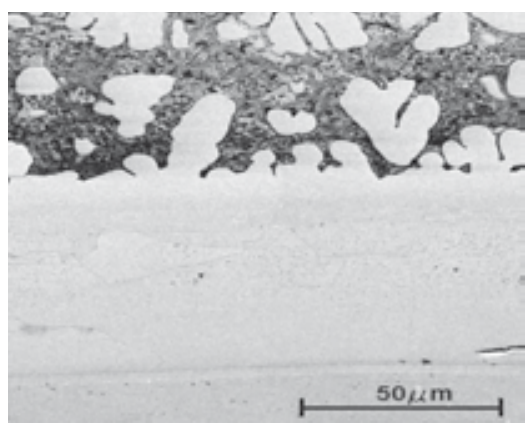

Rys. 9. Mikrostruktura złącza lutowanego (Zn-Al) $)_{\text {eut }}+1,0 \%$ at. Cu na podłożu miedzianym w temperaturze $500^{\circ} \mathrm{C}$, czas ekspozycji $180 \mathrm{~s}$ Fig. 9. Microstructure of solder joints $(\mathrm{Zn}-\mathrm{Al})_{\text {eut }}+1.0 \%$ at. $\mathrm{Cu}$ on the copper substrates at $500^{\circ} \mathrm{C}$, exposure time $180 \mathrm{~s}$

$\gamma-\mathrm{Cu}_{5} \mathrm{Zn}_{8}$. Na tych rysunkach można wyróżnić trzy warstwy faz międzymetalicznych. Od strony podłoża miedzianego są to CuZn, $\mathrm{Cu}_{5} \mathrm{Zn}_{8}, \mathrm{CuZn_{4 }}$. Uzyskane wyniki są zgodne $z$ wynikami zaprezentowanymi w $[11,12]$.

Na rysunkach $10 \div 12$ przedstawiono mikrostrukturę złącza lutowanego $\mathrm{Zn}-\mathrm{Al}+(0,5 ; 1,0 ; 1,5) \%$ at. Cu na podłożu aluminiowym. W trakcie procesu lutowania temperatura wynosiła $500^{\circ} \mathrm{C}$, pomiar odbywał się w powietrzu, użyto topnika Eurotop Al700. Wyniki pomiarów zawartości składu w miejscach zaznaczonych na rysunku 12 przedstawiono $w$ tablicy. Na rysunkach widać, że podłoże Al rozpuszcza się pod wpływem ciekłego lutu - jest to zwilżanie reaktywne. Aluminium z podłoża przechodzi do lutowiny, a zwiększona koncentracja tego pierwiastka występuje w fazach międzymetalicznych (rys. 12, tabl. I).

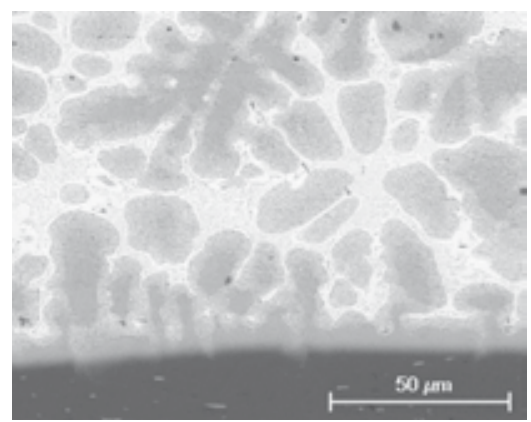

Rys. 10. Mikrostruktura złącza lutowanego $(\mathrm{Zn}-\mathrm{Al})_{\text {eut }}+1,0 \%$ at. Cu na podłożu aluminiowym w temperaturze $500^{\circ} \mathrm{C}$, czas ekspozycji $5 \mathrm{~s}$ Fig. 10. Microstructure of solder joints $(\mathrm{Zn}-\mathrm{Al})_{\text {eut }}+1.0 \%$ at. $\mathrm{Cu}$ on the aluminum substrates at $500^{\circ} \mathrm{C}$, exposure time $5 \mathrm{~s}$

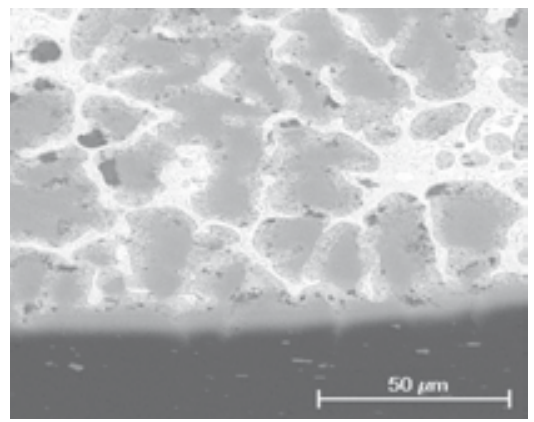

Rys. 11. Mikrostruktura złącza lutowanego (Zn-Al) $)_{\text {eut }}+1,0 \%$ at. Cu na podłożu aluminiowym w temperaturze $500^{\circ} \mathrm{C}$, czas ekspozycji $15 \mathrm{~s}$ Fig. 11. Microstructure of solder joints $(\mathrm{Zn}-\mathrm{Al})_{\text {eut }}+1.0 \%$ at. $\mathrm{Cu}$ on the aluminum substrates at $500^{\circ} \mathrm{C}$, exposure time $15 \mathrm{~s}$ 


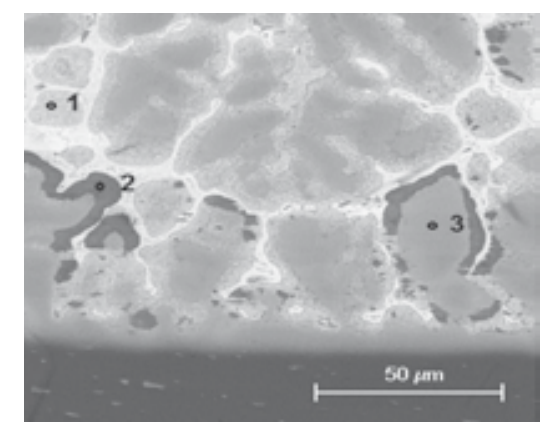

Rys. 12. Mikrostruktura złącza lutowanego $(\mathrm{Zn}-\mathrm{Al})_{\text {eut }}+1,0 \%$ at. $\mathrm{Cu}$ na podłożu aluminiowym w temperaturze $500^{\circ} \mathrm{C}$, czas ekspozycji $30 \mathrm{~s}$ Fig. 12. Microstructure of solder joints $(\mathrm{Zn}-\mathrm{Al})+1.0 \%$ at. $\mathrm{Cu}$ on the aluminum substrates at $500^{\circ} \mathrm{C}$, exposure time $30 \mathrm{~s}$
Tablica I. Analiza mikrostruktury złącza lutowanego (Al-Zn) $)_{\text {eut }}+1,0 \%$ at. Cu na podłożu Al w punktach oznaczonych na rysunku 12

Table I. The microstructure analysis of solder joints $(\mathrm{Al}-\mathrm{Zn})_{\text {eut }}+1.0 \%$ at. $\mathrm{Cu}$ on aluminum substrates which was marked on fig. 12

\begin{tabular}{|c|c|c|c|}
\hline Punkty & Pierwiastek & \% wag. & \% at. \\
\hline \multirow{4}{*}{1} & $\mathrm{Al}$ & 20,47 & 38,39 \\
\cline { 2 - 4 } & $\mathrm{Cu}$ & 1,81 & 1,44 \\
\cline { 2 - 4 } & $\mathrm{Zn}$ & 77,73 & 60,17 \\
\cline { 2 - 4 } & Suma & 100 & 100 \\
\hline \multirow{3}{*}{2} & $\mathrm{Al}$ & 57,43 & 76,46 \\
\cline { 2 - 4 } & $\mathrm{Cu}$ & 3,85 & 2,19 \\
\cline { 2 - 4 } & Zn & 38,72 & 21,35 \\
\cline { 2 - 4 } & Suma & 100 & 100 \\
\hline \multirow{3}{*}{3} & Al & 53,24 & 73,39 \\
\cline { 2 - 4 } & Zn & 46,76 & 26,61 \\
\cline { 2 - 4 } & Suma & 100 & 100 \\
\hline
\end{tabular}

\section{Podsumowanie}

Badano właściwości i zachowanie lutów na bazie eutektyki Zn-Al z różnymi ilościami dodatku miedzi. Stwierdzono, że stopy te zdecydowanie lepiej zwilżają aluminium niż miedź. Świadczy o tym kilkakrotnie mniejszy kąt zwilżania wynoszący dla aluminium $4^{\circ}$, a dla miedzi $20^{\circ}$, oraz przede wszystkim kilkakrotnie większa powierzchnia rozpływu takiej samej ilości lutu $0,5 \mathrm{~g}$ w takiej samej temperaturze $\left(\mathrm{Cu}-\right.$ ok. $90 \mathrm{~mm}^{2}, \mathrm{Al}-$ ok. $\left.300 \mathrm{~mm}^{2}\right)$. Prawdopodobnie decydujący wpływ ma na to większe napięcie powierzchniowe miedzi niż aluminium (dla $\mathrm{Cu}$ $w \mathrm{~T}=1200^{\circ} \mathrm{C}-1154 \mathrm{dyn} / \mathrm{cm}$, dla Al w T $=935^{\circ} \mathrm{C}-463$ $\mathrm{dyn} / \mathrm{cm}$ ), co pokazuje równanie Younga-Laplace'a.
Zasadniczo, niewielkie dodatki miedzi do eutektyki Zn-Al poprawiają właściwości zwilżające lutów zarówno na miedzi, jak i na aluminium. Optymalny wydaje się jednoprocentowy dodatek $\mathrm{Cu}$ do stopu eutektycznego Zn-Al. W przypadku podłoża miedzianego związane jest to prawdopodobnie ze zwiększaniem energii aktywacji faz międzymetalicznych, co powoduje zmniejszenie kinetyki wzrostu. Jeśli chodzi o podłoże aluminiowe, to wiąże się to $z$ tym, że niewielkie dodatki miedzi zwiększają szybkość rozpuszczania aluminium przez ciekły lut.

\section{Literatura}

[1] Dyrektywa 2008/35/WE Parlamentu Europejskiego i Rady z dnia 11 marca $2008 \mathrm{r}$.

[2] Dyrektywa 2002/96/WE Parlamentu Europejskiego i Rady z dnia 27 stycznia $2003 \mathrm{r}$.

[3] Dyrektywa 2003/108/WE Parlamentu Europejskiego i Rady $z$ dnia 8 grudnia $2003 r$

[4] Moser Z., Gasior W., Bukat K., Pstruś J., Kisiel R., Sitek J., Ishida K., Ohnuma I.: Pb-free Solders. Wettability Testing of Sn-Ag-Cu Alloys With Bi Additions. Part I, J. Phase Equilibria and Diffusion, 27, 2006, s.133-139.

[5] Lopez E.P., Vianco P.T., Rejent J.A.: J. Elect. Mater., 34 (2004), 299.

[6] Moser Z., Gąsior W., Pstruś J.: J. Phase Equilibria, 22 (2001) 254.

[7] Moser Z., Gąsior W., Pstruś J, Księżarek S.: J.Electron. Mater. 31 (2002), s.1225.

[8] Rettenmayer M., Lambracht P., Kempf B., Tschudin C.: J. Electron. Mater. 31 (2002), s.279-285.

[9] Shimizu T., Ishikawa H., Ohnuma I., Ishida K.: J. Electron. Mater. 28 (1999), s.1172-1174.
[10] Vianco P. T.: Solder alloys: A look at the past, present and future. Welding Journal $\mathrm{nr}$ 3/1997.

[11] Takaku Y., Felicia L., Ohnuma I., Kainuma R., Ishida K.: Interfacial Reaction Between Cu Substrates and Zn-Al Base High-Temperature Pb-Free Solders; Journal of Electronic Materials, Vol. 37, No. 3, 2008

[12] Kang N., Sung Na H., Kim S.K., Kang C.Y.: Alloy design of $\mathrm{Zn}-\mathrm{Al}-\mathrm{Cu}$ solder for ultra-high temperatures; Journal of Alloys and Compounds 467 (2009), s.246-250.

[13] Savaskan T., Turhal M.S.: Relationships between cooling rate, copper content and mechanical properties of monotectoid based $\mathrm{Zn}-\mathrm{Al}-\mathrm{Cu}$ alloys; Materials Characterization 51 (2003), s.259-270.

[14 ] Gancarz T., Pstruś J., Fima P., Mosińska S.; Thermal Properties and Wetting Behavior of High Temperature Zn-Al-In Solders, Journal of Materials Engineering and Performance; 21 (2012), s.599-605.

[15 ] Klein-Wassink R.J.: Soldering in Electronics, 2nd ed., Electochemical Publications, Ayr, Scotland, 1984. 